\title{
Pattern of Serum Vitamin D in Individuals with non-Alcoholic Fatty Liver and its Relation to Metabolic Dysfunction
}

\author{
Fatma Rageh ${ }^{1}$, Samar S. Ahmed ${ }^{2}$, Shaymaa Abdelraheem Abdelhady ${ }^{3}$, \\ Mohamed Aboelmagd ${ }^{4}$, Mohamed Farrag ${ }^{5}$, Mariam Hassan ${ }^{6}$, Naglaa. \\ Abd Al Monem ${ }^{7}$, Ahmed Abd Elrazik Mohamed ${ }^{8}$, Dalia Ghareeb ${ }^{9}$ \\ ${ }^{1}$ Department of Infectious Diseases, Gastroenterology and Hepatology, Faculty of \\ Medicine, Suez University, Suez, Egypt. \\ ${ }^{2}$ Department of Public Health and Community Medicine, Faculty of Medicine, Suez \\ University, Suez, Egypt. \\ ${ }^{3}$ Department of Clinical Pathology, Faculty of Medicine, Suez Canal University, \\ Ismailia, Egypt. \\ ${ }^{4}$ Department of Endemic and Infectious Diseases, Faculty of Medicine, Suez Canal \\ University, Ismailia, Egypt. \\ ${ }^{5}$ Department of Critical Care Medicine, Faculty of Medicine, Misr University for \\ Science and Technology, Cairo, Egypt . \\ ${ }^{6}$ Department of Internal Medicine, Ahmed Maher Teaching Hospital, Cairo, Egypt. \\ ${ }^{7}$ Department of Tropical Medicine, Faculty of Medicine, Zagazig University, Zagazig, \\ Egypt. \\ ${ }^{8}$ Department of Radiodiagnosis, Alazhar University, Assiut, Egypt. \\ ${ }^{9}$ Department of Clinical Pathology, Faculty of Medicine, Suez University, Suez, Egypt.
}

Corresponding Author Fatma Rageh

Mobile:

$+201126319318$

E mail:

frageh2002@hotmail. com

Key words: fatty liver, vitamin $D$ status, dyslipidemia, obesity, metabolic dysfunction .
Background and study aim: Vitamin D has extensive anti-fibrotic, antiinflammatory, and insulin-sensitizing properties, in addition to involvement in immune-metabolic pathways within the gut-adipose tissue-liver axis. This study aims to assess the association between vitamin D deficiency, metabolic dysfunction and NAFLD which is still controversial.

Patients and Methods: Cross sectional study that included 170 subjects; 85 cases with fatty liver and 85 healthy controls. After measurement of BMI, both studied groups were subjected to the following laboratory investigations: vitamin $\mathrm{D}$, liver enzymes, random blood glucose, HbA1C, cholesterol, TG, LDL, HDL and uric acid.

Results: Vitamin D deficiency was associated with many metabolic dysfunction parameters. Regarding NAFLD: in univariate analysis, vitamin D deficiency, male sex, overweight and obesity, hypercholesterolemia, hyperglycaemia, and elevated liver enzymes were the risk factors. Meanwhile multivariate analysis showed that the risk factors included male sex, overweight and obesity. Sensitivity and specificity of vit $\mathrm{D}$ deficiency, at a cutoff value of $\leq 18.5$ $\mathrm{mg} / \mathrm{mL}$, were $68.24 \%$ and $52.92 \%$, respectively. Sensitivity and specificity of hypertriglyceridemia, with a cutoff value of $>113 \mathrm{mg} / \mathrm{dL}$, were $77.65 \%$ and $48.24 \%$, respectively. At cutoff value of $>5.2 \%$, sensitivity and specificity of HBA1C were $69.41 \%$ and $56.47 \%$, respectively.

Conclusion: Vitamin D deficiency is associated with high prevalence of metabolic changes. Thus, early detection and treatment of such deficiency can improve fatty liver disease and its associated metabolic changes, hence, preventing progression into liver cirrhosis.

\section{INTRODUCTION}

Nonalcoholic fatty liver disease (NAFLD) is accumulation and storage of increased amounts of fat in hepatic cells; which causes liver damage similar to heavy alcoholic consumption with little or no consumption of alcohol. NAFLD has two forms: simple form of hepatic steatosis without inflammation or fibrosis, and progressive form with hepatic inflammation, fibrosis, advanced cirrhosis and liver failure; representing about $10-30 \%$ of NAFLD cases. NAFLD progression is not always linear so it is difficult to predict when and who will progress to advanced stages [1-3]. 
NAFLD is a common health problem; affecting about $25-30 \%$ of people all over the world due to increased rates of obesity. The prevalence of NAFLD has doubled in the previous 20 years with hazardous health consequences $[3,5]$.

NAFLD could be either a result or a cause of metabolic syndrome in most cases associated with diabetes type 2 and dyslipidemia [1]. Nowadays, NAFLD is considered a consequence of metabolic syndrome, insulin resistance or lifestyle-related diseases such as diabetes mellitus (DM), dyslipidemia and hypertension rather than a primary liver disease [6, 7]. The difference in age of onset, sex of cases and severity of NAFLD is related to differences in obesity and metabolic syndrome in the general population $[8,9]$.

Vitamin D has an anti-inflammatory and antifibrotic function on the hepatic stellate cells signifying an association between vitamin D deficiency in NAFLD. However, this association is still unsettled [10].

Recent studies found that fructose metabolism produces uric acid. Both fructose and serum uric acid are associated with NAFLD; as fructose metabolized to triglycerides (TG) in the liver, and subsequently induce hepatic steatosis through mitochondrial oxidative stress and accumulation of hepatic fats [11]. Other possible mechanisms by which uric acid produce NAFLD are insulin resistance and hyperinsulinemia which decrease nitrous oxide supply to the cells [12] and increase of oxidative stress [13]; all of which promote hepatic steatosis [11-13].

Our study aimed to identify association between vitamin $\mathrm{D}$ deficiency and metabolic changes with non-alcoholic fatty liver disease.

\section{PATIENTS AND METHODS}

A cross sectional study conducted between June 2018 and December 2020. It was carried out at the clinic of gastroenterology and hepatology in a specialized hospital. The study included 170 participants involved by convenience sampling: 85 cases of non-alcoholic fatty liver and 85 healthy controls. Sociodemographic data were collected: age, sex, residence, and smoking habits. Weight and height were measured to calculate the body mass index (BMI) by dividing weight in $\mathrm{Kg}$ to square height in meters.
BMI from18.5 to 24.9 was considered normal, > 25 indicated overweight and >30 indicated obesity [14]. Blood pressure was measured by sphygmomanometer and hypertension was considered as $\geq 140 \mathrm{mmHg}$ systolic and $\geq 90$ mmHg diastolic [15].

All the participants underwent an abdominal ultrasound (US) as well as liver function tests to be included in the study. NAFLD diagnosis was established according to the American Association for the Study of Liver Diseases (AASLD), the American College of Gastroenterology, and the American Gastroenterological Association guidelines published in 2012. The diagnosis of NAFLD required: (1) evidence of hepatic steatosis (HS) by imaging ultrasound (2) no significant alcohol consumption, (3) no competing causes of HS, and (4) no coexisting causes of chronic liver disease [16]. Ultrasound features included any 4 of the following 5 sonographic features: (1) attenuation of image quickly within $4-5 \mathrm{~cm}$ of depth; (2) echogenic diffuse but particularly important to note brightness within the first 2-3 $\mathrm{cm}$ of depth; (3) liver uniformly heterogeneous; (4) thick subcutaneous depth (>2 cm); and (5) liver fills entire field with no visible edges [17].

Patients with chronic viral hepatitis, liver cirrhosis secondary to any cause, patients with history of primary biliary cirrhosis, primary sclerosing cholangitis, and patients with heart or respiratory or renal diseases as well as pregnant women were excluded from the study. In addition, patients on calcium or vitamin D supplementation or any patients that received vitamin D supplement in the previous 2 months as vit D has a lengthy half-life [ $\underline{\mathbf{1 8}}]$ were also excluded from the study.

All study populations were subjected to the following laboratory investigations:

- Random blood glucose (RBG), HbA1c, uric acid, liver enzymes: ALT and AST, lipid profile: cholesterol, TG, LDL and HDL. They were measured using fully automated analyzer Cobas 8000 (Roche Diagnostics, Mannheim, Germany).

- Vitamin D level in addition was estimated using Abbott Architect i-2000SR (Abbott Park, IL, USA). Architect 25-OH Vitamin D assay is a quantitative chemiluminescent microparticle immunoassay permitted by FDA to measure 25hydroxyvitamin D in serum. Principle of the test 
is depending on that the sample and pretreatment reagents are mixed with assay diluent then combine with paramagnetic anti-vitamin D coated microparticles to make a reaction mixture. Vitamin D in the sample then bind to antivitamin $\mathrm{D}$ coated microparticles. After incubation anti-Biotin acridinium-labeled conjugate complex is added to the reaction mixture and fixes to unoccupied binding sites of the anti-vitamin D coated microparticles. Pretrigger and trigger solutions are added after washing. The reaction then is measured as relative light units (RLUs). An indirect relationship presents between the quantity of vitamin D in the serum and the RLUs sensed by the Architect i System optics.

Vitamin D level was classified into three categories as following: sufficient if more than $30 \mathrm{ng} / \mathrm{ml}$, insufficient from 20 to $30 \mathrm{ng} / \mathrm{ml}$ and deficient less than $20 \mathrm{ng} / \mathrm{ml}$ [19].

\section{Statistical analysis:}

Data were analyzed using IBM SPSS software package version 20.0. (Armonk, NY: IBM Corp). Kolmogorov- Smirnov test normality distribution of variables. Student t-test was used to compare two groups in normally distributed quantitative variables, while Mann Whitney test was used for non-normal distributed quantitative variables. Chi-square test was done in categorical variables. Results Significance was judged at 5\% level.

Odds ratio was used to estimate risk factors led to fatty liver. Also, the effect of vitamin D on blood sugar, blood lipids and uric acid assessed by regression analysis. Sensitivity and specificity for different parameters affecting NAFLD were estimated.

Ethical consideration: The study had ethics approval from the associated institutions and was done according to Helsinki Declaration. All patients signed a written informed consent before inclusion into this study. Privacy and confidentiality of patients were kept. Approval from the manager of the private hospital and Ethical Committee of Faculty of Medicine, Suez University was obtained.

\section{RESULTS:}

Demographics, medical history and laboratory findings were compared between both groups. NAFLD group was younger in age and most of them were males. That group had higher BMI, liver enzymes, uric acid, RBS, HBAIC, and more impaired lipid profile. All these variables were significantly different between both groups, except for residence, smoking, hypertension, and mean LDL and HDL levels (Table 1).

Three fourths of NAFLD group had vitamin D deficiency in comparison to only $58 \%$ of control group. Only $7.1 \%$ of NAFLD group had sufficient vitamin D level; in contrast to $22.4 \%$ in the other group. This difference was statistically significant $(P=0.01))$.

Univariate analysis showed that important risk factors of fatty liver were vitamin D deficiency, male sex, overweight, hypercholesteremia, hyperglycemia and elevated liver enzymes meanwhile multivariate analysis shows that only male sex and overweight were risk factors of NAFLD (Table 2).

Subgroup analysis of patients with NAFLD based on vitamin D level status revealed that cholesterol level, triglycerides, random blood sugar (RBS), hypertension (HTN) and overweight were higher in the deficient group, but the difference was not statistically significant (Table 3).

Meanwhile, when we compared vitamin D deficient cases with those with insufficient or normal level among all participants, we found that BMI, RBS, hypercholesterolemia, hypertriglyceridemia and LDL were significantly higher in the deficient group. Although $\mathrm{HbA} 1 \mathrm{C}$, ALT and AST, uric acid and HTN were higher in the deficient groups than those with insufficient or normal level, the difference was statistically insignificant.

Using receiver operating characteristic (ROC) statistics; to show the predictors of NAFLD, showed that sensitivity and specificity of vitamin D deficiency, at a cutoff value of $\leq 18.5 \mathrm{ng} / \mathrm{mL}$, were $68.24 \%$ and $52.92 \%$, respectively. Sensitivity and specificity of hypertriglyceridemia, at a cutoff value of $>113$, were $77.65 \%$ and $48.24 \%$, respectively. Sensitivity and specificity of HBA1C, at a cutoff value of $>5.2 \mathrm{mg} / \mathrm{L}$, were $69.41 \%$ and $56.47 \%$, respectively. While, sensitivity and specificity of hypercholesterolemia, at a cutoff value of $>190$, were $61.18 \%$ and $50.59 \%$, respectively. This indicated that hypertriglyceridemia, $\mathrm{HbA} 1 \mathrm{c}$ and Vitamin D deficiency (77.6, 69.4, and 68.2\%) respectively were the most sensitive indicator and predictive of NAFLD (Table 4; Figure 1,2). 
Table (1): Comparison between the study groups according to different parameters

\begin{tabular}{|c|c|c|c|}
\hline & NAFLD $(n=85)$ & Control $(n=85)$ & $P$ value \\
\hline $\begin{array}{l}\text { Age (years) } \\
\text { Mean } \pm \text { SD. }\end{array}$ & $36.1 \pm 9.2$ & $40 \pm 12.1$ & $0.020^{*}$ \\
\hline \begin{tabular}{|l|} 
Sex \\
Male \\
Female \\
\end{tabular} & $\begin{array}{l}49(57.6 \%) \\
36(42.4 \%) \\
\end{array}$ & $\begin{array}{l}30(35.3 \%) \\
55(64.7 \%) \\
\end{array}$ & $0.003^{*}$ \\
\hline $\begin{array}{l}\text { Residence } \\
\text { Urban } \\
\text { Rural }\end{array}$ & $\begin{array}{l}62(72.9 \%) \\
23(27.1 \%)\end{array}$ & $\begin{array}{l}68(80 \%) \\
17(20 \%)\end{array}$ & 0.278 \\
\hline $\begin{array}{l}\text { Smoking } \\
\text { Yes } \\
\text { No }\end{array}$ & $\begin{array}{l}23(27.1 \%) \\
62(72.9 \%)\end{array}$ & $\begin{array}{l}27(31.8 \%) \\
58(68.2 \%)\end{array}$ & 0.501 \\
\hline $\begin{array}{l}\text { BMI }\left(\mathbf{k g} / \mathbf{m}^{2}\right) \\
\text { Normal } \\
\text { Over weight } \\
\end{array}$ & $\begin{array}{l}16(18.8 \%) \\
69(81.2 \%) \\
\end{array}$ & $\begin{array}{l}63(74.1 \%) \\
22(25.9 \%) \\
\end{array}$ & $<0.001^{*}$ \\
\hline $\begin{array}{l}\text { Hypertension } \\
\text { Yes } \\
\text { No } \\
\end{array}$ & $\begin{array}{l}17(20 \%) \\
68(80 \%) \\
\end{array}$ & $\begin{array}{l}19(22.4 \%) \\
66(77.6 \%)\end{array}$ & 0.707 \\
\hline $\begin{array}{l}\text { Vit D } \\
\text { Mean } \pm \text { SD. }\end{array}$ & $16.3 \pm 7.7$ & $20.6 \pm 10$ & $0.004^{*}$ \\
\hline $\begin{array}{l}\text { ALT (U/L) } \\
\text { Mean } \pm \text { SD. }\end{array}$ & $43.2 \pm 36.7$ & $26.2 \pm 11.4$ & $<0.001^{*}$ \\
\hline $\begin{array}{l}\text { AST (U/L) } \\
\text { Mean } \pm \text { SD. }\end{array}$ & $35.9 \pm 25.6$ & $22.5 \pm 9.2$ & $<0.001^{*}$ \\
\hline $\begin{array}{l}\text { RBS } \\
\text { Mean } \pm \text { SD. }\end{array}$ & $148 \pm 59.6$ & $128.7 \pm 53.2$ & $0.013^{*}$ \\
\hline $\begin{array}{l}\text { HBA1C } \\
\text { Mean } \pm \text { SD. }\end{array}$ & $6 \pm 1.4$ & $5.5 \pm 1.1$ & $0.001^{*}$ \\
\hline $\begin{array}{l}\text { Cholesterol (mg/dl) } \\
\text { Mean } \pm \text { SD. }\end{array}$ & $218 \pm 57.4$ & $190.1 \pm 46.4$ & $0.004^{*}$ \\
\hline $\begin{array}{l}\text { Triglyceride (mg/dl) } \\
\text { Mean } \pm \text { SD. }\end{array}$ & $177 \pm 92.2$ & $146.1 \pm 75.4$ & $0.010^{*}$ \\
\hline $\begin{array}{l}\text { LDL }(\mathbf{m g} / \mathbf{d l}) \\
\text { Mean } \pm \text { SD. }\end{array}$ & $115.2 \pm 42.2$ & $105.5 \pm 47.6$ & 0.100 \\
\hline $\begin{array}{l}\text { HDL (mg/dl) } \\
\text { Mean } \pm \text { SD. }\end{array}$ & $57.6 \pm 25.9$ & $63.8 \pm 25.4$ & 0.078 \\
\hline $\begin{array}{l}\text { Uric acid } \\
\text { Mean } \pm \text { SD. }\end{array}$ & $5.2 \pm 1.2$ & $4.8 \pm 1.4$ & $0.037^{*}$ \\
\hline
\end{tabular}

*: Statistically significant at $\mathrm{p} \leq \mathbf{0 . 0 5}$

Table (2): Univariate and multivariate Logistic regression analysis for the parameters affecting NAFLD group $(\mathbf{n}=\mathbf{8 5})$

\begin{tabular}{|l|c|c|c|c|}
\hline \multirow{2}{*}{} & \multicolumn{2}{|c|}{ Univariate } & \multicolumn{2}{c|}{ Multivariate } \\
\cline { 2 - 5 } & OR (95\% C.I) & p & OR (95\% C.I) & P \\
\hline Sex (male) & $2.49(1.34-4.63)$ & $0.004^{*}$ & $2.67(1.17-6.09)$ & $0.019^{*}$ \\
\hline BMI (kg/m $)^{2}$ Overweight & $12.35(5.96-25.54)$ & $<0.001^{*}$ & $11.30(4.63-27.61)$ & $<0.001^{*}$ \\
\hline Hypercholesteremia & $3.43(1.36-8.61)$ & $0.009^{*}$ & $1.21(0.38-3.88)$ & 0.743 \\
\hline High TG & $1.61(0.88-2.95)$ & 0.125 & & 0.126 \\
\hline Hitamin D deficiency & $2.13(1.12-4.11)$ & $0.023^{*}$ & $2.00(0.82-4.87)$ & 0.840 \\
\hline High HbA1C & $2.28(1.20-4.34)$ & $0.012^{*}$ & $0.91(0.38-2.18)$ & \\
\hline High ALT & $1.90(0.75-4.79)$ & 0.175 & & 0.061 \\
\hline High AST & $4.35(2.26-8.38)$ & $<0.001^{*}$ & $2.57(0.95-6.91)$ & 0.063 \\
\hline High Uric acid & $4.94(2.30-10.63)$ & $<0.001^{*}$ & $2.93(0.94-9.11)$ & \\
\hline
\end{tabular}

\footnotetext{
*: Statistically significant at $\mathrm{p} \leq 0.05$
} 
Table (3): Relation between Vita5min D and different parameters in the NAFLD group

\begin{tabular}{|c|c|c|c|}
\hline & & evel & \\
\hline & $\begin{array}{c}\text { Deficient } \\
(n=64)\end{array}$ & $\begin{array}{c}\text { Insufficient + sufficient } \\
(\mathrm{n}=\mathbf{2 1})\end{array}$ & $\mathbf{p}$ \\
\hline $\begin{array}{l}\text { Age (years) } \\
\text { Mean } \pm \text { SD }\end{array}$ & $35.2 \pm 9$ & $39 \pm 9.3$ & 0.270 \\
\hline $\begin{array}{l}\text { Sex } \\
\text { Male } \\
\text { Female }\end{array}$ & $\begin{array}{l}35(54.7 \%) \\
29(45.3 \%)\end{array}$ & $\begin{array}{c}14(66.7 \%) \\
7(33.3 \%)\end{array}$ & 0.335 \\
\hline $\begin{array}{l}\text { Residence } \\
\text { Urban } \\
\text { Rural }\end{array}$ & $\begin{array}{l}45(70.3 \%) \\
19(29.7 \%)\end{array}$ & $\begin{array}{c}17(81 \%) \\
4(19 \%)\end{array}$ & 0.341 \\
\hline $\begin{array}{l}\text { Smoking } \\
\text { Yes } \\
\text { No }\end{array}$ & $\begin{array}{l}16(25 \%) \\
48(75 \%) \\
\end{array}$ & $\begin{array}{c}7(33.3 \%) \\
14(66.7 \%)\end{array}$ & 0.456 \\
\hline $\begin{array}{l}\text { BMI }\left(\mathbf{k g} / \mathbf{m}^{2}\right) \\
\text { Normal } \\
\text { Over weight }\end{array}$ & $\begin{array}{l}11(17.2 \%) \\
53(82.8 \%)\end{array}$ & $\begin{array}{c}5(23.8 \%) \\
16(76.2 \%)\end{array}$ & 0.528 \\
\hline $\begin{array}{l}\text { HTN } \\
\text { Yes } \\
\text { No } \\
\end{array}$ & $\begin{array}{l}14(21.9 \%) \\
50(78.1 \%) \\
\end{array}$ & $\begin{array}{c}3(14.3 \%) \\
18(85.7 \%) \\
\end{array}$ & 0.545 \\
\hline $\begin{array}{l}\mathbf{A L T}(\mathbf{U} / \mathbf{L}) \\
\text { Mean } \pm \text { SD. }\end{array}$ & $42.2 \pm 40.2$ & $46 \pm 23.3$ & 0.114 \\
\hline $\begin{array}{l}\text { AST (U/L) } \\
\text { Mean } \pm \text { SD. }\end{array}$ & $35.4 \pm 27.9$ & $37.3 \pm 17.7$ & 0.221 \\
\hline $\begin{array}{l}\text { RBS }\left(\times 10^{3} / \boldsymbol{\mu l}\right) \\
\text { Mean } \pm \text { SD. }\end{array}$ & $152 \pm 62.1$ & $136 \pm 50.7$ & 0.294 \\
\hline $\begin{array}{l}\text { HBA1C } \\
\text { Mean } \pm \text { SD }\end{array}$ & $6 \pm 1.5$ & $6 \pm 1.3$ & 0.675 \\
\hline $\begin{array}{l}\text { Cholesterol (mg/dl) } \\
\text { Mean } \pm \text { SD. }\end{array}$ & $223.9 \pm 60.3$ & $200 \pm 43.5$ & 0.102 \\
\hline $\begin{array}{l}\text { Triglceride (mg/dl) } \\
\text { Mean } \pm \text { SD. }\end{array}$ & $188.8 \pm 97.8$ & $141 \pm 61.7$ & 0.057 \\
\hline $\begin{array}{l}\text { LDL (mg/dl) } \\
\text { Mean } \pm \text { SD. }\end{array}$ & $117.9 \pm 43.3$ & $107 \pm 38.3$ & 0.386 \\
\hline $\begin{array}{l}\text { HDL }(\mathbf{m g} / \mathbf{d l}) \\
\text { Mean } \pm \text { SD. }\end{array}$ & $57.3 \pm 27.2$ & $58.2 \pm 22.2$ & 0.919 \\
\hline $\begin{array}{l}\text { Uric acid } \\
\text { Mean } \pm S D\end{array}$ & $5.1 \pm 1.2$ & $5.5 \pm 1.3$ & 0.268 \\
\hline
\end{tabular}

Table (4): Validity (AUC, sensitivity, specificity) for different parameters as a predictors of NAFLD $(n=85)$ from control $(n=85)$

\begin{tabular}{|c|c|c|c|c|c|c|c|c|}
\hline & $\begin{array}{l}\text { Cut off } \\
\text { value }\end{array}$ & AUC & $\mathbf{p}$ & 95\% C.I & 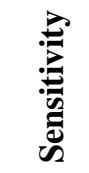 & 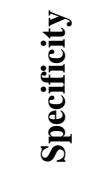 & $\vec{a}$ & $\frac{2}{z}$ \\
\hline$\overline{\operatorname{ALT}(\mathbf{U} / \mathbf{L})}$ & $>28$ & 0.68 & $<0.001^{*}$ & $0.59-0.76$ & 62.35 & 57.65 & 59.6 & 60.5 \\
\hline $\operatorname{AST}(\mathbf{U} / \mathbf{L})$ & $>22$ & 0.68 & $<0.001^{*}$ & $0.60-0.76$ & 64.71 & 51.76 & 57.3 & 59.5 \\
\hline $\operatorname{RBS}\left(\times 10^{3} / \mu \mathrm{l}\right)$ & $>119$ & 0.61 & $0.013^{*}$ & $0.52-0.69$ & 60.0 & 60.0 & 60.0 & 60.0 \\
\hline HBA1C & $>5.2$ & 0.65 & $0.001^{*}$ & $0.56-0.73$ & 69.41 & 56.47 & 61.5 & 64.9 \\
\hline \begin{tabular}{|l|} 
Cholesterol (mg/dl) \\
\end{tabular} & $>190$ & 0.63 & $0.004^{*}$ & $0.54-0.71$ & 61.18 & 50.59 & 55.3 & 56.6 \\
\hline Triglyceride (mg/dl) & $>113$ & 0.61 & $0.010^{*}$ & $0.53-0.70$ & 77.65 & 48.24 & 60.0 & 68.3 \\
\hline Vit D & $\leq 18.5$ & 0.62 & $0.004^{*}$ & $0.54-0.71$ & 68.24 & 52.94 & 59.2 & 62.5 \\
\hline
\end{tabular}

AUC: Area Under a Curve, NPV: Negative predictive value, PPV: Positive predictive value *: Statistically significant at $\mathrm{p} \leq 0.05$ \#Cut off point was choosen according to Youden index 


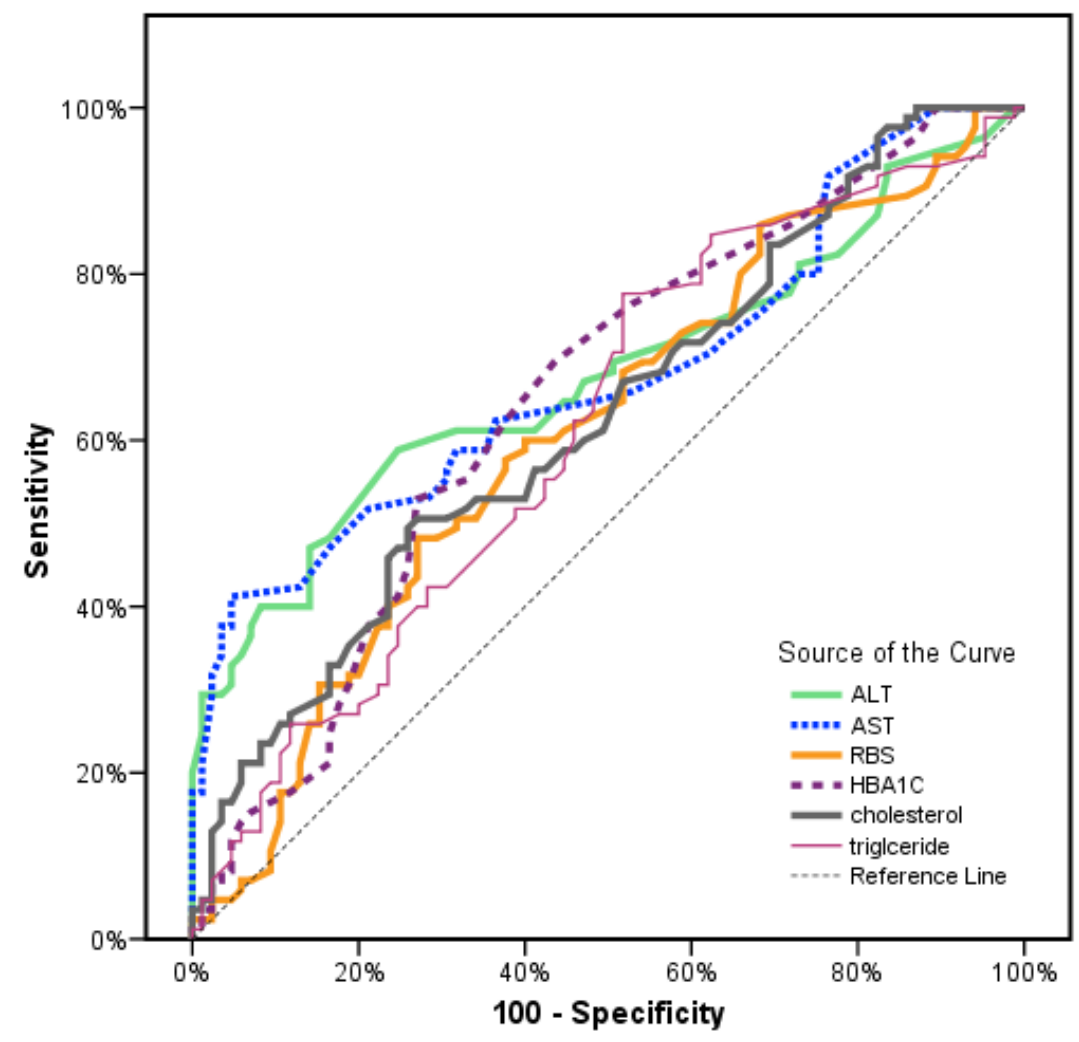

Figure (1): ROC curve for different parameters as a predictors of NAFLD $(n=85)$ from control $(\mathbf{n}=\mathbf{8 5})$

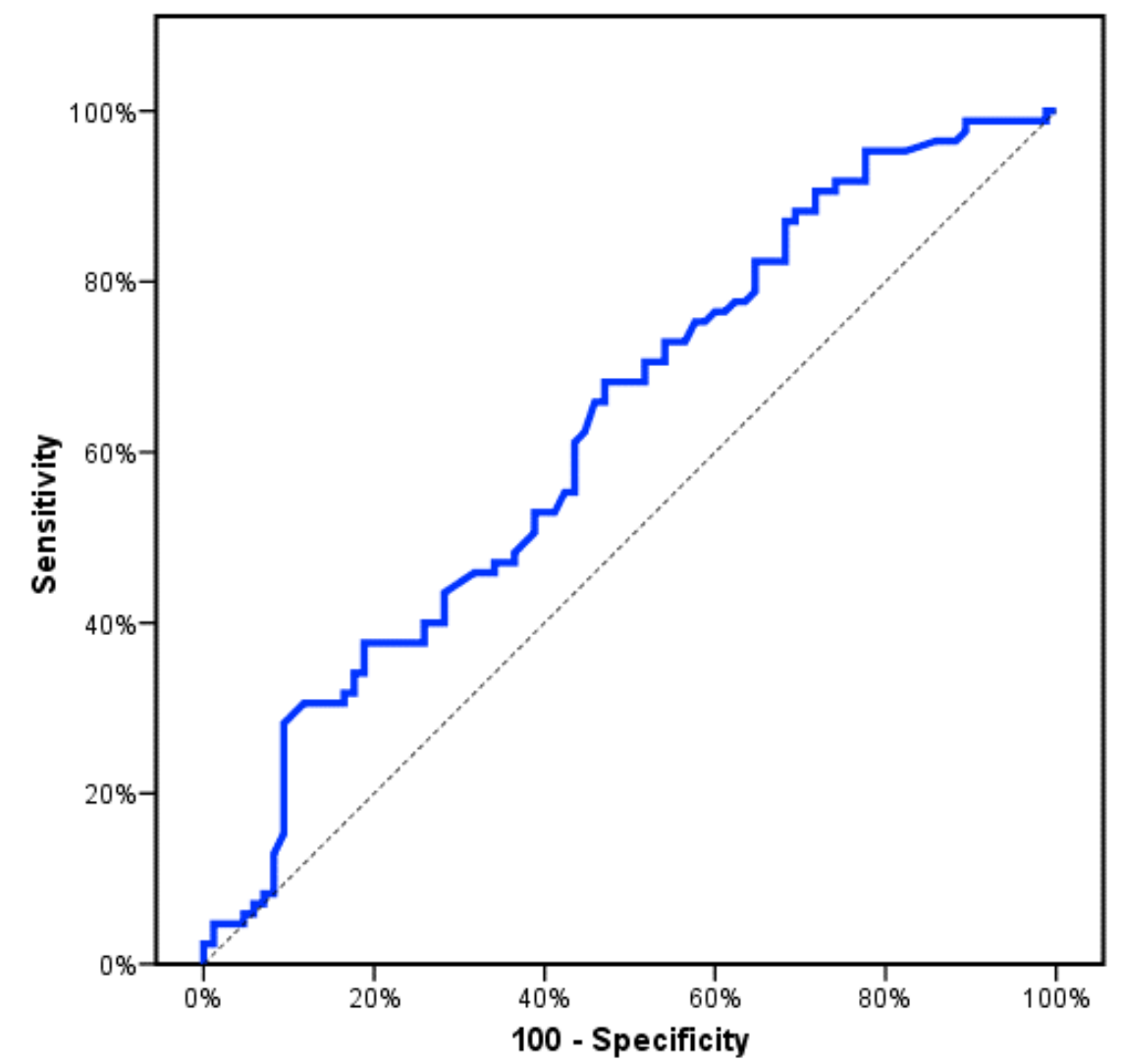

Figure (2): ROC curve for Vit D as a predictor to NAFLD $(n=85)$ from control $(n=85)$ 


\section{DISCUSSION}

As the worldwide prevalence of nonalcoholic fatty liver disease has doubled in the previous 20 years with hazardous health consequences, it is important to study all its aspects. Several studies explored the association between vitamin D status and NAFLD with contradictory results. This case control study identified association between vitamin $\mathrm{D}$ deficiency and associated metabolic changes of NAFLD.

Vitamin D deficiency has been linked to various health problems including obesity, diabetes mellitus, cardiac diseases, cancer, auto immune diseases, chronic liver diseases especially liver cirrhosis and NAFLD [20]. In this study, the mean value of vitamin $D$ level was lower in NAFLD group than in the control group. This finding agreed with Ehrampoush et al. [21] as they found that vitamin D level was (15.84 \pm $5.50 \mathrm{ng} / \mathrm{ml}$ versus $26.77 \pm 8.26 \mathrm{ng} / \mathrm{ml}$ ) and $\mathrm{Gad}$ [22] $(16.13 \pm 10.23 \mathrm{ng} / \mathrm{ml}$ versus $27.35 \pm 10.58$ $\mathrm{ng} / \mathrm{ml}$ ), in cases versus controls; respectively,. In a systemic review of 45 studies conducted by Pacifico and colleagues [23]; nearly two thirds of these studies showed that vitamin D deficiency associated with NAFLD. That conclusion was supported by Barchetta et al. [24] and Chung et al. [25] who found inverse relationship between Vitamin D level and severity of liver diseases; regardless of their causes; viral or metabolic hepatitis or NAFLD. All the previous studies were in line with the study findings; as it found that vitamin D was significantly associated with NAFLD cases with double risk in those deficient persons $(\mathrm{OR}=2.13)$. On the contrary, some studies reached to different findings than the study results. For instance, Jaruvongvanich et al. [26], Bril et al. [27], and Patel et al. [28], didn't demonstrate an association or correlation between vitamin D level and NAFLD and fats deposition in liver nor with NAFLD. Furthermore, an Italian controlled study showed that even vitamin D supplementation had no effect on metabolic or cardiovascular parameters or hepatic steatosis [29].

One important factor that was associated with NAFLD is obesity, which runs in epidemics or even pandemics in many countries. It is worthy to mention that some epidemiological studies linked both low vitamin D levels and NAFLD [30] with obesity (high BMI). This is explained by the fact that alpha-hydroxylase activity is decreased in fatty liver resulting in biotransformation of calciferol into inactive forms and decreases bioavailability of vitamin D, and in turn increases its requirement in obese who are also disposed to NAFLD. Interestingly, it was reported that weight loss increases vitamin D level without supplementation and improve metabolic functions in patients with NAFLD [31]. It is also known that Vitamin D is one of fat-soluble vitamins and it is stored in adipose tissue and there are accumulating evidence that vitamin $\mathrm{D}$ in the form of 25 hydroxy cholecalciferol is inversely correlated with the amount of fats and obesity. This is also may be explained by sedentary life of obese persons with less exposure of sunlight and decreased synthesis of endogenous vitamin D [32].

Overweight and obesity presented by increase BMI in the current study was in a highly significant association with NAFLD with 11-12 folds increased risk of NAFLD in overweight persons. These findings agreed partially with a population-based study done on 1812 subjects with NAFLD. They found that male sex, BMI higher than $28 \mathrm{~kg} / \mathrm{m} 2, \quad \mathrm{DM}$ and higher triglyceride level had significant association with NAFLD cases, while Vitamin D insufficiency was not associated with NAFLD [33]. This study findings also agreed with findings of Lin et al. [34] study where age, gender, BMI, cholesterol were significant risk factors of NAFLD. In addition, Lin et al. [34], showed that nearly 50$80 \%$ had central obesity and DM type 2, suggesting that using metabolic risk factors with elevated liver enzymes is promising in identifying NAFLD patients.

In the current study, low serum vitamin D was significantly associated with hyperlipidemia (hypercholesteremia and higher LDL). This was in line with previous studies, especially among overweight and obese subjects [30-32], In contrast, Black et al found that low serum vitamin $\mathrm{D}$ was evident among NAFLD patients independent of their BMI [35]. These contrasting results might be attributed to different study populations as the latter study was conducted among adolescents rather than adults.

One of the risk factors that we investigated was hypertension, it found that it had no significant association with vitamin D deficiency among study participants, including those with NAFLD. This agreed with Catena et al. [36] who found that low vitamin D was not associated with hypertension among patients with and without 
NAFLD. In contrast, Borges-Canha et al. [37] reported that in patients with NAFLD, low vitamin $\mathrm{D}$ was associated with higher prevalence of hypertension. In fact, different sample sizes are a contributing factor to this discrepancy.

In this study, patients with NAFLD had significantly higher liver enzymes; however, this impairment was not statistically significant among patients with vitamin D deficiency. These study results came in agreement with Skaaby et al. [38] who found that vitamin D level was in a converse relationship with liver enzymes; but this relation was insignificant. Similarly, many studies proved that vitamin D supplementation for patients with concurrent vitamin D deficiency and NAFLD did not improve the concentration of ALT or AST [39]. Nevertheless, some studies found that vitamin D supplements improved steatosis grade [40].

Concerning vitamin D level and blood glucose level, we found that RBS was significantly higher among patients with NAFLD; especially those with vitamin $D$ deficiency. It is well known that NAFLD is associated with impaired glucose insulin homeostasis [41]. This agrees with Cai et al [42], as they found that patients with severe forms of NAFLD had higher mean of fasting blood glucose FBG and HBA1C as well. In addition, they also found that high FBG and HBA1C were independent risk factors of low vitamin D. Similarly, in an Egyptian study by Hosny et al. [43], it was found that vitamin D deficiency was more prevalent among patients with concomitant NAFLD and DM. A recent meta-analysis explored this relation on a large scale of participants and found that vitamin D supplementation improved glucose insulin metabolism [44].

The study demonstrated significant association between NAFLD and serum uric acid SUA level, which synchronized with other study findings. For example, Yang et al. [45] showed that serum uric acid was significantly associated with NAFLD. Lombardi [46] found an association between increased SUA and the development of NAFLD. In addition, Lombardi [46] revealed that SUA could be considered as a predictor for the severity of NAFLD and liver damage. This is justified because uric acid is generated from fructose metabolism, and both associated with NAFLD; as fructose produce fatty liver through polyol pathway [47].
In this study, we investigated predictors of NAFLD, and we found that male gender, high BMI, hypercholesteremia, high RBS, high ALT and high AST were significant predictors of NAFLD. These predictors were of a similar sensitivity and specificity; but triglycerides, HbA1c and Vitamin D were the most sensitive and specific variables. Zhang et al. [48] found that vitamin D level was a significant predictor of NAFLD. El-Karaksy [49] found that BMI and lipid profile were good predictors of NAFLD as well.

\section{CONCLUSIONS:}

It is concluded that vitamin D deficiency is associated with high prevalence of metabolic changes and it is adjuvant factors to nonalcoholic fatty liver disease. Overweight, obesity and hypercholesteremia are highly associated with NAFLD in addition to increase of TG and increase of blood sugar presented by high level of RBS and $\mathrm{HbA} 1 \mathrm{C}$.

Strengths and limitations of the study: Strengths include different parameters that lead to fatty liver were studied. Limitations include study inability to be generalized beyond the Suez governorate; in particular beyond the private center of hepatology.

\section{Recommendations:}

General recommendation is to have ideal body weight and set all precautions measures to prevent overweight and obesity. It is also recommended to early treat hypercholesteremia and hypertriglyceridemia before fatty liver develops. Early detection of vitamin D deficiency and sunlight exposure are advised.

Funding: no external fund.

Conflicts of interest: The authors declare that they have no conflict of interest.

\section{REFERENCES}

1. Younossi ZM, Loomba R, Anstee QM, Rinella ME, Bugianesi E, Marchesini G, et al. Diagnostic modalities for nonalcoholic fatty liver disease, nonalcoholic steatohepatitis, and associated fibrosis. Hepatology 2018; 68:349-360

2. Hashimoto E, Tokushige K, Ludwig J. Diagnosis and classification of non-alcoholic fatty liver disease and non-alcoholic steatohepatitis: Current concepts and remaining challenges. Hepatology Research 2015; 45: 20-28. 
3. Dyson J, Anstee Q, McPherson S. Non-alcoholic fatty liver disease: a practical approach to diagnosis and staging. Frontline Gastroenterol 2014; 5:211-218.

4. Ng M, Fleming $\mathrm{T}$, Robinson $\mathrm{M}$, Thomson B, Graetz N, Margono C, et al. Global, regional, and national prevalence of overweight and obesity in children and adults during 1980-2013: a systematic analysis for the Global Burden of Disease Study 2013. Lancet 2014; 384:766-781.

5. Vernon G, Baranova A, Younossi ZM. Systematic review: the epidemiology and natural history of non-alcoholic fatty liver disease and non-alcoholic steatohepatitis in adults. Aliment Pharmacol Ther 2011; 34: 274-85.

6. Fu JF, Shi HB, Liu LR. Non-alcoholic fatty liver disease: an early mediator predicting metabolic syndrome in obese children? World $J$ Gastroenterol 2011; 17: 735-42.

7. Siddiqui MS, Sterling RK, Luketic VA. Association between high-normal levels of alanine aminotransferaseand risk factors for atherogenesis. Gastroenterology 2013; 145: 1271-9.

8. Hashimoto E, Tokushige K. Prevalence, gender, ethnic variations, and prognosis of NASH. $J$ Gastroenterol 2011; 46(1): 63-9.

9. Kogiso T, Hashimoto E, Tokushige K. Characteristics of gender differences and age in nonalcoholic steatohepatitis with regard to the complications of lifestyle-related disease, fat distribution, adipocytokines and SNPs. Kazo 2014; 55: 199-205.

10. Abramovitch S, Dahan-Bachar L, Sharvit E, Weisman Y, Tov AB, Brazowski E, et al. Vitamin $\mathrm{D}$ inhibits proliferation and profibrotic marker expression in hepatic stellate cells and decreases thioacetamide-induced liver fibrosis in rats. Gut 2011; 60:1728-1737.

11. Wang Y, Zheng X, Gong L, Lou R, Chen Hua, Ren W. et al. Serum uric acid and non-alcoholic fatty liver disease in non-obesity Chinese adults. Lipids Health Dis 2017; 16, no: 202.

12. Wan X, Xu C, Lin Y, Lu C, Li D, Sang J, et al. Uric acid regulates hepatic steatosis and insulin resistance through the NLRP3 inflammasomedependent mechanism. J Hepatol 2016; 64(4):925-32.

13. Choi YJ, Shin HS, Choi HS, Park JW, Jo I, Oh ES, et al. Uric acid induces fat accumulation via generation of endoplasmic reticulum stress and SREBP-1c activation in hepatocytes. Lab Investig 2014; 94: 1114-25.

14. Body mass index - BMI [Internet]. Euro.who.int. 2021 [cited 3 July 2021]. Available from: https://www.euro.who.int/en/health- topics/disease-prevention/nutrition/a-healthylifestyle/body-mass-index-bmi?source=post_page

15. Unger T, Borghi C, Charchar F, Khan NA , Poulter NR, Prabhakaran D, et al. International Society of Hypertension Global Hypertension Practice Guidelines. Hypertension 2020; 75:13341357.

16. Ando Y, Jou J H. Nonalcoholic Fatty Liver Disease and Recent Guideline Updates. Clin Liver Dis 2021; 17(1):23-28.

17. Riley TR, Mendoza A, Bruno MA. Bedside ultrasound can predict nonalcoholic fatty liver disease in the hands of clinicians using a prototype image. Dig Dis Sci 2006; 51:982-985.

18. Institute of medicine, food and nutrition board. Dietry reference intakes for calcium and vitamin D,Washington,DC:Natinal Academy Press, 2010,

19. Holick MF, Binkley NC, Bischoff-Ferrari HA, Gordon CM, Hanley DA, Heaney RP, et al. Evaluation, treatment, and prevention of vitamin D deficiency: An endocrine society clinical practice guideline. J Clin Endocrinol Metab 2011; 96: 1911-1930.

20. Theodoratou E, Tzoulaki I, Zgaga L, Ioannidis JP. Vitamin D and multiple health outcomes: Umbrella review of systematic reviews and metaanalyses of observational studies and randomized trials. BMJ 2014; 348:g2035.

21. Ehrampoush E, Ghaemi A, Osati S, Maleki M, RaeisiShahraki H, Honarvar B, et al. The association between serum vitamin $\mathrm{D}$ level and nonalcoholic fatty liver disease. Hepat Mon 2019; 19(9):e92992.

22. Gad AI, Elmedames MR, Abdelhai AR, Marei AM. The association between vitamin D status and non-alcoholic fatty liver disease in adults: a hospital-based study. EGLJ 2020; 10(25):1-8.

23. Pacifico L, Osborn JF, Bonci E, Pierimarchi P, Chiesa C. Association between vitamin D levels and nonalcoholic fatty liver disease: potential confounding variables. Mini-Reviews Med Chem. 2019; 19:310-332

24. Barchetta I, Carotti S, Labbadia G, Gentilucci UV, Muda AO, Angelico F, et al. Liver vitamin D receptor, cyp2r1, and cyp27a1 expression: Relationship with liver histology and vitamin D3 levels in patients with nonalcoholic steatohepatitis or hepatitis c virus. Hepatology 2012; 56:21802187.

25. Chung GE, Kim D, Kwak MS, Yang JI, Yim JY, Lim SH, et al. The serum vitamin D level is inversely correlated with nonalcoholic fatty liver disease. Clin Mol Hepatol 2016; 22:146-151. 
26. Jaruvongvanich V, Ahuja W, Sanguankeo A, Wijarnpreecha K, Upala S. Vitamin D and histologic severity of nonalcoholic fatty liver disease: a systematic review and meta-analysis. Dig Liver Dis 2017; 49:618-622v3.

27. Bril F, Maximos M, Portillo-Sanchez P, Biernacki D, Lomonaco R, Subbarayan S, et al. Relationship of vitamin $\mathrm{D}$ with insulin resistance and disease severity in non-alcoholic steatohepatitis. J Hepatol 2015; 62:405-411.

28. Patel YA, Henao R, Moylan CA, Guy CD, Piercy DL, Diehl AM, et al. Vitamin D is not associated with severity in NAFLD: Results of a paired clinical and gene expression profile analysis. Am J Gastroenterol 2016; 111:1591-1598.

29. Barchetta I, Del Ben M, Angelico F, Di Martino M, Fraioli A, La Torre G, et al. No effects of oral vitamin $\mathrm{D}$ supplementation on non-alcoholic fatty liver disease in patients with type 2 diabetes: A randomized, double-blind, placebo-controlled trial. BMC Med. 2016; 14: 92.

30. Lee SM, Jun DW, Cho YK, Kyun Y, Seol K. Vitamin D deficiency in non-alcoholic fatty liver disease: The chicken or the egg? Clin Nutr 2017; 36(1):191-197.

31. Vimaleswaran KS, Berry DJ, Lu C, Tikkanen E, Pilz S, Hiraki LT, et al. Causal relationship between obesity and vitamin $\mathrm{D}$ status: bidirectional Mendelian randomization analysis of multiple cohorts. PLoS Med 2013; 10:e1001383.

32. Zakharova I, Klimov L, Kuryaninova V, Niktina I, Malyavskaya S, Dolbnya S, et al. Vitamin D Insufficiency in Overweight and Obese Children and Adolescents. Inter relationship between Vitamin D and Adipose Tissue. Front. Endocrinol 2019; 10:103

33. Ha Y, Hwang S G, and Rim K S. The Association between Vitamin D Insufficiency and Nonalcoholic Fatty Liver Disease: A PopulationBased Study. Nutrients 2017; 9(8): 806.

34. Lin YC, Chou SC, Huang PT, Chiou HY. Risk factors and predictors of non-alcoholic fatty liver disease in Taiwan. Ann Hepatol 2011; 10(2):125132.

35. Black LJ, Jacoby P, She Ping-Delfos WC, Mori TA, Beilin LJ, Olynyk JK, et al. Low serum 25hydroxyvitamin D concentrations associate with non-alcoholic fatty liver disease in adolescents independent of adiposity. J. Gastroenterol Hepatol 2014; 29:1215-1222.

36. Catena C, Cosma C, Camozzi V, Plebani M, Ermani M, Sechi LA, et al. Non-alcoholic fatty liver disease is not associated with vitamin D deficiency in essential hypertension. High Blood Press Cardiovasc Prev. 2013; 20(1):33-7.
37. Borges-Canha M, Neves JS, Mendonça F, Silva MM, Costa C, Cabral PM, et al. The Impact of Vitamin D in Non-Alcoholic Fatty Liver Disease: A Cross-Sectional Study in Patients with Morbid Obesity. Diabetes Metab Syndr Obes 2021; 14:487-495.

38. Skaaby T, Husemoen L, Borglykke A, Jørgensen $\mathrm{T}$, Thuesen $\mathrm{BH}$, Pisinger $\mathrm{C}$, et al. vitamin D status, liver enzymes, and incident liver disease and mortality: a general population study. Endocrine 2014; 47(1):213-220.

39. Hajiaghamohammadi A, Shafikhani A, Bastani A, Gaemi N. effect of vitamin D replacement on liver enzymes in patients with non-alcoholic fatty liver disease. Journal of GHR 2019;8(3):2907-2910.

40. Jamil R, Mofid A, Vahedi H, Farzaneh R, Dowlatshahi S. The effect of Helicobacter pylori eradication on liver fat content in subjects with non-alcoholic fatty liver disease: a randomized open-label clinical trial. Hepat Mon 2013; 13(12):e14679.

41. European Association for the Study of the Liver (EASL) European Association for the Study of Diabetes (EASD) European Association for the Study of Obesity (EASO) EASL-EASD-EASO clinical practice guidelines for the management of non-alcoholic fatty liver disease. J Hepatol 2016; 64:1388-1402.

42. Cai J, Zhang Z, Liu J, Xiao X, Wang C, Deng M, et al. Correlation between serum $25 \mathrm{OH}$ vitamin $\mathrm{D}$ expression and non alcoholic fatty liver disease. Exp Ther Med 2020; 19(3):1681-1686.

43. Hosny S, Ali H, Mohammed W, El Ghannam M. Study of relationship between total vitamin D level and NAFLD in a sample of Egyptian patients with and without T2DM, Diabetes \& Metabolic Syndrome. Clinical Research \& Reviews, 2019; 13(3):1769-1771.

44. Guo XF, Wang C, Yang T, Li S, Li K, Li D. Vitamin D and non-alcoholic fatty liver disease: A meta-analysis of randomized controlled trials. Food Funct. 2020; 11:7389-7399.

45. Yang H, Li D, Song X, Liu F, Wang X, Ma Q, et al. Joint associations of serum uric acid and ALT with NAFLD in elderly men and women: a Chinese cross-sectional study. J Transl Med. 2018; 17; 16(1):285.

46. Darmawan G, Hamijoyo L, Hassan I. Association between Serum Uric Acid and Non-Alcoholic Fatty Liver Disease: A Meta-Analysis. Acta Med Indones. 2017; 49(2):136-147.

47. Lombardi R, Pisano G, Fargion S. Role of Serum Uric Acid and Ferritin in the Development and Progression of NAFLD. Int J Mol Sci. 2016; 12; 17(4):548. 
48. Zhang Y, Li J, Ni Y, Wang Y, Liu H. Correlational study on the levels of 25hydroxyvitamin D and non-alcoholic fatty liver disease in type 2 diabetic patients. BMC Endocr Disord 2021; 18; 21(1):100.
49. El-Karaksy HM, El-Koofy NM, Anwar GM, ElMougy FM, El-Hennawy A, Fahmy ME. Predictors of non-alcoholic fatty liver disease in obese and overweight Egyptian children: single center study. Saudi J Gastroenterol 2011; 17(1):40-46. 